\title{
EFEITOS DA ADIÇÃO DO RESÍDUO DE CORTE DE MÁRMORE E GRANITO (RCMG) NO DESEMPENHO DS ARGAMASSAS DE CIMENTO PORTLAND NO ESTADO ENDURECIDO
}

\author{
Vanessa Ribeiro Peixoto da Matta
}

\author{
Elenice Carmo de Abreu Apolinário
}

\section{Gabriel Ricardo Silva Santos}

\section{Daniel Véras Ribeiro}

RESUMO: O ambiente construído do futuro está sendo edificado no começo de uma nova era ecológica, na qual a construção civil deve alinhar seus benefícios à sociedade com a necessidade de tornar suas práticas mais sustentáveis a longo prazo. Entre as medidas cabíveis para alcançar o patamar da sustentabilidade está o reaproveitamento de resíduos sólidos como matérias-primas alternativas na produção de materiais inovadores. A indústria de rochas ornamentais no Brasil produz quantidades significativas de rejeitos que podem ser empregados como adições minerais em matrizes cimentíceas. Neste estudo, verificou-se o efeito da adição do resíduo de corte de mármore e granito (RCMG) nas principais propriedades das argamassas de cimento Portland no estado endurecido. Os teores de adição variaram de $0 \%$ a $15 \%$ (em massa) e a relação água/cimento (a/c = $0,59)$ foi fixada como parâmetro de controle. Em seguida, foi avaliado o comportamento das argamassas quanto à resistência mecânica e parâmetros de durabilidade. Os 
resultados obtidos mostram que as propriedades das argamassas são otimizadas com a adição de 5\% do resíduo, atestando que o uso do RCMG como filler é uma alternativa viável de destinação ambientalmente adequada para este resíduo.

Palavras-chave: Resíduos. Mármore e granito. Argamassas. Desempenho.

\section{INTRODUÇÃO}

A crescente geração de resíduos sólidos resulta em significativa degradação ambiental e é uma realidade alarmante ao redor mundo. A Europa foi responsável por gerar 3 bilhões de toneladas de rejeitos em 2006 (EUROPEAN COMMISSION, 2012). Em 2011, no Brasil, foram geradas 61,9 milhões de toneladas de resíduos sólidos, 1,8\% a mais do que no ano anterior (ABRELPE, 2012). Esse incremento é superior ao crescimento da própria população brasileira, que foi de $0,8 \%$ no mesmo período, de acordo com dados do IBGE. Percebe-se que é premente a necessidade de adotarem-se medidas para conter a geração desenfreada de resíduos pela sociedade, assim como de melhorar os sistemas de gestão de resíduos sólidos já existentes.

De acordo com a Organização das Nações Unidas, o desenvolvimento sustentável é "aquele que atende às necessidades do presente sem comprometer a possibilidade de as gerações futuras atenderem às suas próprias necessidades" (ONU, 1991). Isso implica em aumentar a produção de bens a partir de uma menor quantidade de recursos naturais e diminuir a poluição nesse processo (JOHN, 2000). Assim, entre as medidas a serem tomadas estão o aumento da durabilidade dos produtos, a partir do uso de materiais mais eficientes, e o desenvolvimento de materiais inovadores e tecnologias alternativas, capazes de absorver os resíduos sólidos como complemento ou substituição das matérias-primas convencionais.

A construção civil é, hoje, a maior consumidora de matérias-primas do mundo, empregando, em suas diversas atividades, cerca de $50 \%$ dos recursos naturais extraídos 
Volume 9, Número 1, 2013

Aplicação de Novas

Tecnologias Sustentáveis

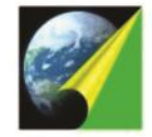

ANAP

anualmente (SOUZA \& DEANA, 2007). A maior parte desses recursos destina-se à produção de concretos e argamassas, materiais extensivamente empregados em edificações e na construção pesada. Em contrapartida, o fato de consumir um significativo volume de recursos também torna a construção civil um dos setores tecnológicos mais indicados para absorver os resíduos sólidos oriundos de processos industriais.

Dentre esses rejeitos está o resíduo proveniente do beneficiamento de rochas ornamentais, sobretudo mármore e granito, materiais extensivamente empregados em edificações e elementos decorativos. Na etapa de beneficiamento primário (corte), em que os blocos de rocha são desdobrados em chapas nas serrarias, é gerado um alto volume de resíduo em forma de lama abrasiva, composto por pó da rocha, água, cal e granalha. Considerando que de $20 \%$ a $30 \%$ dos blocos de rocha são reduzidos a pó durante a serragem (GONÇALVES, 2000), pode-se estimar que, em 2011, ano em que a produção nacional de rochas atingiu 9 milhões de toneladas, foram gerados por volta de 2 milhões de toneladas de resíduo de corte. Carentes de valor comercial, os rejeitos são depositados em aterros, bota-foras de material de construção ou lançados em rios, córregos ou esgotos. Com o objetivo de conferir uma destinação final adequada a este abundante resíduo, seu emprego como matéria-prima alternativa, sobretudo no âmbito dos materiais de construção, vem sendo investigado por diversos pesquisadores. Sabe-se que a composição química do resíduo é um indicador de sua compatibilidade com as matrizes cimentíceas, e sua forma granular com elevada finura o torna um material com bom potencial de utilização como adição mineral em concretos e argamassas, podendo agir como fíller (GONÇALVES, 2000; MENEZES et al., 2009; ARUNTAŞ et al., 2010; CORINALDESI et al., 2010).

Este trabalho teve como objetivo avaliar a viabilidade técnica do uso do resíduo de corte de mármore e granito (RCMG) como adição a argamassas de cimento Portland. Foram adotados teores de 5\%, 10\% e 15\% de adição do resíduo, em relação à massa de cimento, para argamassas de cimento e areia sem o uso de aditivos. Estas foram analisadas quanto ao desempenho mecânico e parâmetros de durabilidade. Os resultados 
desses testes permitiram verificar o efeito da adição nas principais propriedades das argamassas, assim como identificar o teor ótimo de adição às argamassas.

\section{MATERIAIS E MÉTODOS}

\subsection{Materiais}

Foram utilizados o cimento CP-II Z 32 da marca Poty, areia natural quartzosa, resíduo de corte de mármore e granito (RCMG) e água proveniente da rede pública de abastecimento da Empresa Baiana de Água e Saneamento S.A. - Embasa.

O resíduo, coletado na forma de lama, foi gerado durante a etapa de corte das rochas e é formado por uma proporção não definida de mármore e granito. Assim, sua composição química pode apresentar variabilidade a depender do lote em estudo, como é comum ao tratar-se de resíduos de processos industriais.

\subsection{Métodos}

\subsubsection{Caracterização das Matérias-Primas}

A análise granulométrica da areia foi realizada através de peneiramento manual conforme a NBR NM 248:2003 ("Agregados - Determinação da composição granulométrica"), a massa específica foi determinada pelo método do frasco de Chapman e a massa unitária pelo procedimento da NBR NM 45:2006 ("Agregados - Determinação da massa unitária e do volume de vazios").

A caracterização física do cimento CP I| Z 32 RS e a do RCMG foram realizadas pelo Laboratório de Formulação e Síntese Cerâmica da Universidade Federal de São Carlos (LAFSCer - UFSCar). A massa específica foi obtida mediante a um picnômetro a gás hélio, a distribuição do tamanho de partículas foi obtida com o auxílio de um sedígrafo 
- Horiba CAPA-700 - e a área superficial BET com o auxílio do aparelho Gemini 2370 V1.02, da Micrometrics. A caracterização mineralógica foi determinada por difração de raios-X (DRX), com o auxílio de um difratômetro - Rigaku Geirgeflex ME 210GF2 pertencente ao Instituto de Física da Universidade de São Paulo (IFUSP), e a composição química foi determinada pelo SGS GEOSOL Laboratórios Ltda., por meio da técnica de fluorescência de raios-X (FRX).

\subsubsection{Formulação e Preparo das Argamassas}

Definiu-se, inicialmente, o traço $1,00: 2,60: 0,59$ (cimento : areia : água), sobre o qual foi acrescida a quantidade de resíduo referente a cada composição $(0 \%$ - referência $-, 5 \%, 10 \%$ e $15 \%$ em relação à massa de cimento). A relação água/cimento foi mantida constante e não foram empregados aditivos para uniformização da consistência.

As misturas foram realizadas mecanicamente, em betoneira, durante um tempo de 4 a 5 minutos. Foram confeccionados corpos de prova prismáticos $(4 \mathrm{~cm} \times 4 \mathrm{~cm} \times 16$ $\mathrm{cm})$ e cilíndricos $(5 \mathrm{~cm} \times 10 \mathrm{~cm})$, adensados em mesa vibratória. A desmoldagem dos espécimes foi realizada após $24 \mathrm{~h}$ e estes foram submetidos à cura imersa até que atingissem as idades de ensaio.

\subsubsection{Análise de Desempenho}

\section{a) Resistência mecânica}

Os ensaios de resistência mecânica foram realizados nas idades de 3, 7, 28 e 63 dias. Para cada composição, os exemplares prismáticos foram utilizados para avaliar a resistência à tração na flexão $\left[R_{t, F}\right.$, Equação (1)]. Após a ruptura por flexão, as metades de cada corpo de prova foram novamente utilizadas para a determinação do limite de resistência à compressão axial $\left(R_{c}\right)$, calculado pela Equação (2): 


$$
\begin{aligned}
R_{t, F} & =\frac{1,5 P L_{A}}{40^{3}} \\
R_{C} & =\frac{P}{1600}
\end{aligned}
$$

onde, $\mathrm{P}=$ carga máxima de ruptura e ;

$L_{A}=$ distância entre os apoios no ensaio de flexão.

\section{b) Densidade e porosidade aparentes}

As medidas de densidade e porosidade aparentes foram realizadas em exemplares com 28 dias de idade. $O$ procedimento adotado baseia-se no princípio de Arquimedes e inicia-se com a determinação da massa seca $\left(m_{s}\right)$ dos espécimes. Em seguida, os corpos de prova são imersos em água até a saturação (48h), quando são determinadas a massa imersa $\left(m_{i}\right)$ e a massa saturada $\left(m_{\text {sat }}\right)$. A porosidade aparente $\left(P_{A}\right)$ e a densidade aparente $\left(D_{A}\right)$ são calculadas com o auxílio das Equação (3) e Equação (4).

$$
\begin{gathered}
P_{A}=100 \frac{m_{\text {sat }}-m_{s}}{m_{s a t}-m_{i}}(\%) \\
D_{A}=\rho_{L} \frac{m_{s}}{m_{s a t}-m_{i}}
\end{gathered}
$$

\section{c) Absorção de água por capilaridade}

Três corpos de prova cilíndricos de cada composição foram utilizados para o ensaio, realizado na idade de 28 dias, de acordo com a NBR 9779/1995 ("Argamassa e concreto endurecido - Determinação da absorção de água por capilaridade"). O coeficiente de absorção capilar ou absortividade corresponde ao coeficiente angular do trecho retilíneo da curva de absorção, até o ponto a partir do qual é verificada a mudança da declividade da curva (ponto de saturação), conforme a Equação (5):

$$
i=B+S \cdot t^{1 / 2}
$$

onde, $\mathrm{i}=$ absorção $\left(\mathrm{kg} / \mathrm{m}^{2}\right)$; 
$\mathrm{B}=$ coeficiente linear da reta, termo obtido experimentalmente;

$\mathrm{S}=$ absortividade $\left(\mathrm{kg} / \mathrm{m}^{2} \cdot \mathrm{min}^{0,5}\right)$;

$\mathrm{t}=$ tempo $(\mathrm{min})$.

d) Velocidade de propagação de onda ultrassônica e módulo de deformação dinâmico

A velocidade de propagação de uma onda ultrassônica em um meio sólido depende das características deste, como sua densidade de massa e módulo de elasticidade. De forma resumida, quanto mais denso for o meio, maior a velocidade de propagação e maior o módulo de elasticidade desse meio sólido. Assim, a velocidade de propagação pode ser empregada para estimar a condição do material quanto à sua densidade, porosidade e deformabilidade. É calculada pela Equação (6), onde L é o comprimento do corpo de prova e t, o tempo decorrido entre a emissão e a recepção do pulso.

$$
V=L / t
$$

O procedimento consiste na aplicação direta dos dois transdutores (emissor e receptor) nas extremidades dos corpos de prova. $\mathrm{Na}$ tela do aparelho, é possível aferir o tempo decorrido entre a emissão e a recepção do pulso. $O$ ensaio foi realizado em três corpos de prova cilíndricos de cada composição, aos 28 dias de idade

O ensaio de propagação de onda ultrassônica permite, também, avaliar o módulo de deformação dinâmico $\left(E_{d}\right)$, ou rigidez, de um material, através do critério de cálculo expresso pela NBR 15630/2008 ("Argamassa para assentamento e revestimento de paredes e tetos - Determinação do módulo de elasticidade dinâmico através da propagação de onda ultra-sônica'), mostrado na Equação (7).

$$
E_{d}=\rho V^{2} \frac{(1+v)(1-2 v)}{(1-v)}
$$

onde, $\rho=$ densidade de massa no estado endurecido; 
$\mathrm{V}=$ velocidade do pulso;

$V=$ coeficiente de Poisson, adotado como 0,2 na referida norma.

Visto que grande parte das manifestações patológicas nos revestimentos argamassados é desencadeada pelo surgimento de fissuras, o módulo de deformação das argamassas é um parâmetro de grande interesse. Nos revestimentos, a relação entre a área e o volume do material aplicado é elevada, de modo que as solicitações provenientes das movimentações e ações da base exercem grande influência sobre a argamassa. $\mathrm{O}$ surgimento de fissuras é decorrente da elasticidade e resistência à tração inadequadas, sendo necessário determinar um nível de deformabilidade adequado para que o desempenho do sistema de revestimento seja aceitável.

\section{RESULTADOS E DISCUSSÃO}

\subsection{Caracterização das Matérias-Primas}

A areia natural utilizada possui massa unitária de $1,59 \mathrm{~kg} / \mathrm{dm}^{3}$, massa específica de 2,62 kg/ $\mathrm{dm}^{3}$, módulo de finura igual a 1,70, dimensão máxima característica de 2,36 $\mathrm{mm}$ e um teor de $1,3 \%$ de material pulverulento.

O cimento utilizado, CP-II Z 32 da marca Poty, apresentou área superficial de 1,09 $\mathrm{m}^{2} / \mathrm{g}$, massa unitária de $1,00 \mathrm{~kg} / \mathrm{dm}^{3}$ e massa específica de $3,25 \mathrm{~kg} / \mathrm{dm}^{3}$. Sua composição química é apresentada na Tabela 1, onde PF é a perda ao fogo.

Tabela 1 - Composição química do cimento CP-II Z 32, obtida por FRX.

\begin{tabular}{|c|c|c|c|c|c|c|c|c|c|}
\hline Constituinte & $\mathrm{CaO}$ & $\mathrm{SiO}_{2}$ & $\mathrm{Al}_{2} \mathrm{O}_{3}$ & $\mathrm{MgO}$ & $\mathrm{Fe}_{2} \mathrm{O}_{3}$ & $\mathrm{SO}_{3}$ & $\mathrm{~K}_{2} \mathrm{O}$ & $\mathrm{Na}_{2} \mathrm{O}$ & $\mathrm{PF}$ \\
\hline Teor $(\%)$ & 56,0 & 24,5 & 6,1 & 4,0 & 2,5 & 1,8 & 0,25 & 0,45 & 4,1 \\
\hline
\end{tabular}

A massa específica do $R C M G$ é de $2,92 \mathrm{~kg} / \mathrm{dm}^{3}$ e sua área superficial é de 3,54 $\mathrm{m}^{2} / \mathrm{g}$. Por ser muito fino e possuir grande área superficial, o resíduo tem a capacidade de 
absorver uma grande quantidade de água. Na Figura 1 são apresentadas as curvas de distribuição de tamanho de partículas do resíduo, do cimento CP-II Z 32 e da areia. O diâmetro médio das partículas (D50) do RCMG é de $12 \mu \mathrm{m}$, ao passo que, para o cimento, esse valor é de $50 \mu \mathrm{m}$. O RCMG é, assim, mais fino que o cimento, apropriado para o uso como filler.

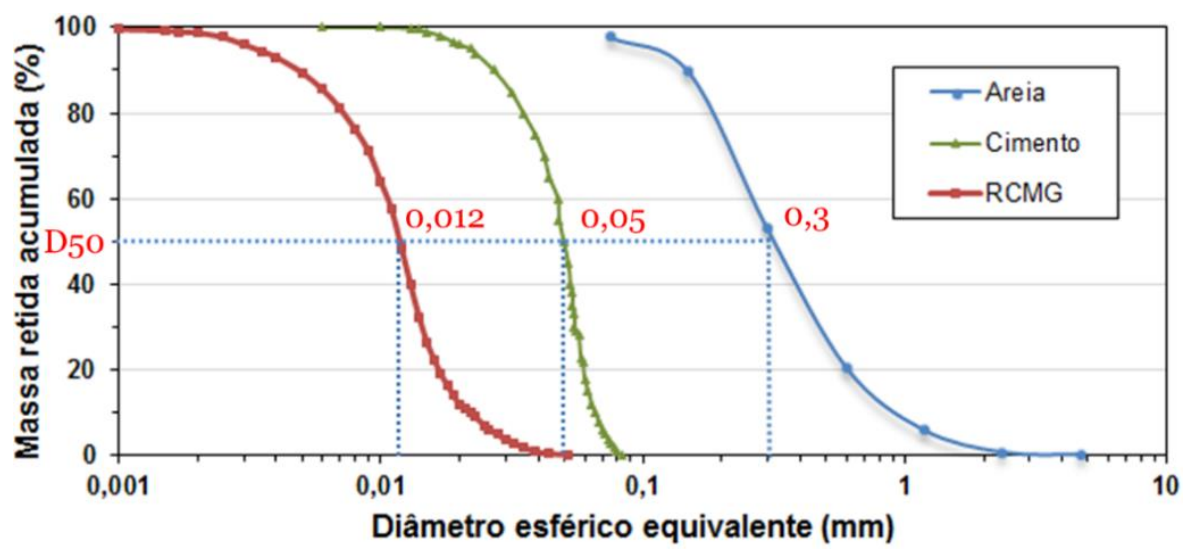

Figura 1 - Distribuição do tamanho de partículas do cimento Portland CP-II Z 32 da marca Poty, obtida pelo ensaio de sedimentação, da areia, obtida pelo peneiramento manual, e do RCMG.

A composição química do RCMG é apresentada na Tabela 3, onde observa-se a predominância da sílica $\left(\mathrm{SiO}_{2}\right)$, óxido de cálcio $(\mathrm{CaO})$ e alumina $\left(\mathrm{Al}_{2} \mathrm{O}_{3}\right)$ como seus principais constituintes, além do óxido férrico $\left(\mathrm{Fe}_{2} \mathrm{O}_{3}\right)$, proveniente do desgaste das lâminas de corte.

Tabela 3 - Composição química do RCMG, obtida por FRX.

\begin{tabular}{|c|c|c|c|c|c|c|c|c|c|c|c|}
\hline Composto & $\mathrm{SiO}_{2}$ & $\mathrm{CaO}$ & $\mathrm{Al}_{2} \mathrm{O}_{3}$ & $\mathrm{MgO}$ & $\mathrm{Fe}_{2} \mathrm{O}_{3}$ & $\mathrm{~K}_{2} \mathrm{O}$ & $\mathrm{Na}_{2} \mathrm{O}$ & $\mathrm{TiO}_{2}$ & $\mathrm{P}_{2} \mathrm{O}_{5}$ & $\mathrm{MnO}$ & $\mathrm{PF}$ \\
\hline Teor $(\%)$ & 37,60 & 17,70 & 9,04 & 8,21 & 4,89 & 2,5 & 1,79 & 0,78 & 0,33 & 0,07 & 17,29 \\
\hline
\end{tabular}

O arranjo desses elementos na formação de fases cristalográficas do material é ilustrado no difratograma de raios $X$ (Fig. 2). Constatou-se a ocorrência de minerais 
tipicamente componentes do granito, como quartzo $\left(\mathrm{SiO}_{2}\right)$, aluminossilicatos de cálcio $\left(\mathrm{CaAl}_{2} \mathrm{Si}_{2} \mathrm{O}_{8}\right)$ e flogopita (mineral da família das micas, classe dos filossilicatos, de fórmula química $\left.\mathrm{KMg}_{3}\left(\mathrm{Si}_{3} \mathrm{Al}\right) \mathrm{O}_{10}(\mathrm{OH})_{2}\right)$, assim como de dolomita, $\left(\mathrm{CaMg}\left(\mathrm{CO}_{3}\right)_{2}\right)$, devido à presença de mármore.

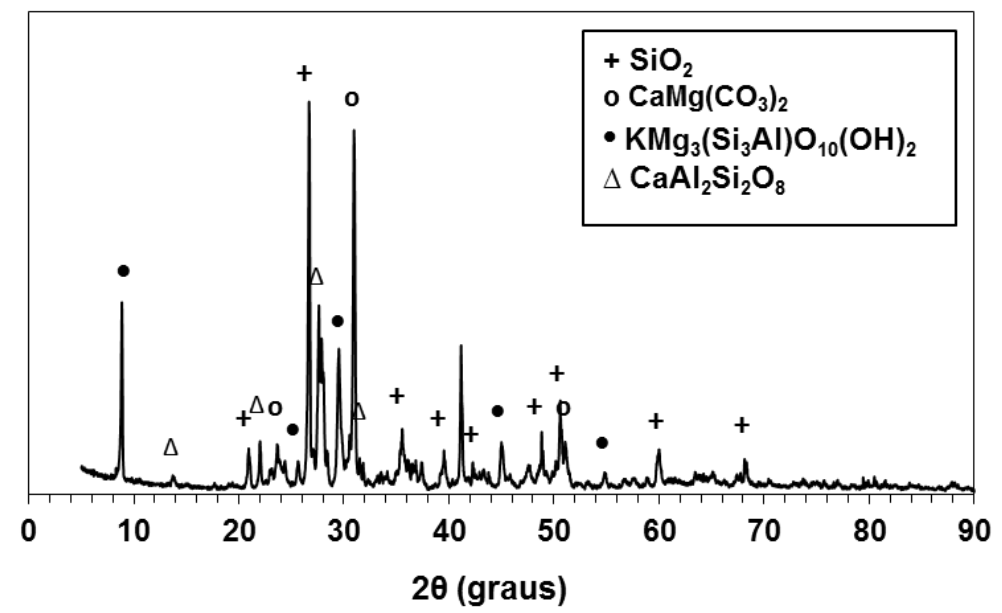

Figura 2 - Difratograma de raios-X do RCMG.

\subsection{Análise de Desempenho}

\subsubsection{Resistência mecânica}

A Figura 3 mostra a evolução da resistência à tração na flexão das argamassas no decorrer das idades de ensaio (3, 7, 28 e 63 dias), em função do teor de RCMG adicionado. Observa-se que, aos 63 dias, a resistência média das argamassas contendo o resíduo supera o valor de referência em até $12,1 \%$, no caso da composição contendo $5 \%$ de adição de RCMG (8,70 MPa contra 7,76 MPa). Isso contraria o observado por Gonçalves (2000), que sugere que pequenos teores de adição do RCMG em argamassas (até 20\%) não alteram o comportamento destas quanto à resistência à tração na flexão, por melhorarem muito pouco o empacotamento das partículas. 


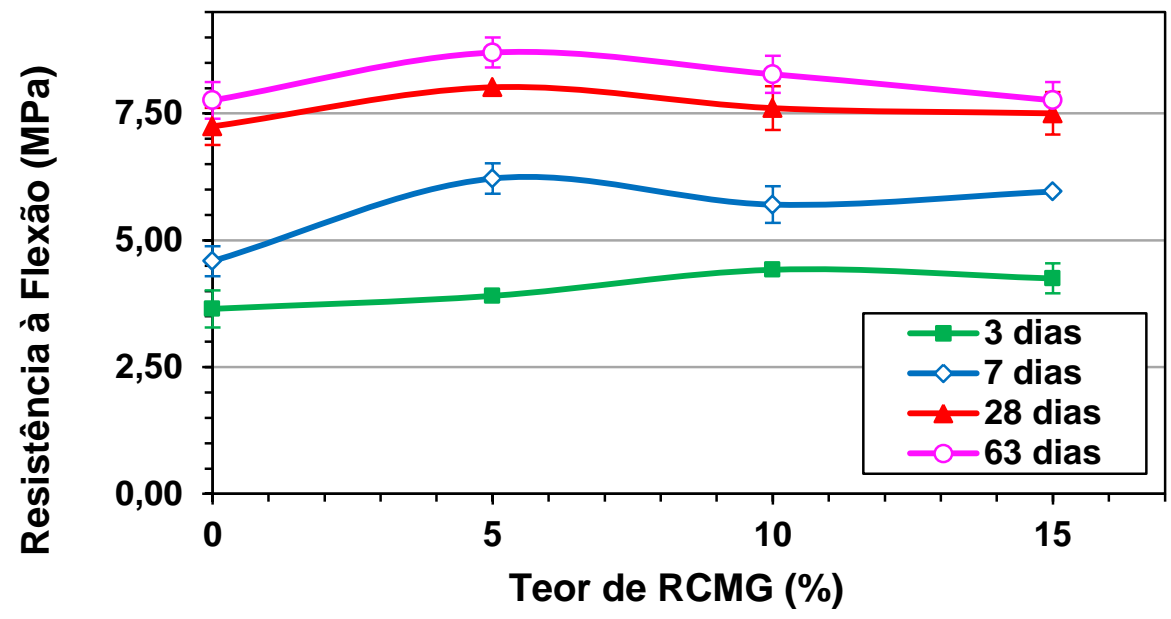

Figura 3 - Evolução da resistência à tração na flexão das argamassas em função do teor de RCMG adicionado.

Após o rompimento por flexão, as metades de cada corpo de prova foram submetidas à compressão axial. A evolução da resistência à compressão axial é ilustrada na Figura 4. É observada uma tendência similar à constatada nos resultados de resistência à tração na flexão. Constatou-se que a adição do resíduo tende a elevar a resistência das argamassas até um valor máximo, de pico, a partir do qual este passa a decrescer. Aos 63 dias, obteve-se um ganho de resistência à compressão da ordem de $9,2 \%$ para teores de adição de até $5 \%$, em relação à argamassa de controle (de 24,3 $\mathrm{MPa}$ para $26,5 \mathrm{MPa})$.

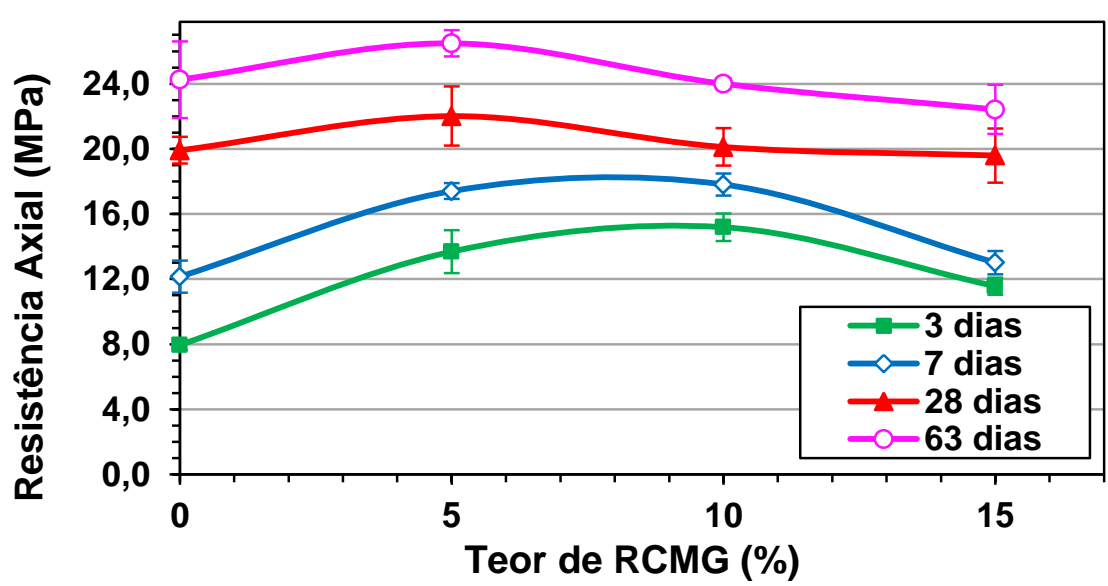


Figura 4 - Evolução da resistência à compressão das argamassas em função do teor de RCMG adicionado.

As partículas finas inertes tendem a preencher os espaços vazios existentes, aumentando a densidade e compacidade do material, aumentando a resistência. A diminuição da resistência para teores de adição superiores a $5 \%$ é justificada pela provável formação de aglomerados de partículas do resíduo, devido à sua dispersão inadequada durante a mistura. O resíduo é composto de partículas de elevada finura, que tendem a se aglomerar e reter parte da água de amassamento, influenciando a reologia da pasta e, principalmente, reduzindo a água disponível para as reações de hidratação do cimento. Já no estado endurecido, os aglomerados equivalem a partículas vazias que, devido à falta de coesão, prejudicam a resistência mecânica (CASTRO \& PANDOLFELLI, 2009).

\subsubsection{Densidade e porosidade aparentes}

As Figuras 5 (a e b) apresentam, respectivamente, a evolução da densidade e porosidade aparentes das argamassas aos 28 dias, em função dos teores de RCMG adicionados. Como esperado, teores crescentes de adição promovem uma maior compacidade da argamassa, devido ao seu efeito fíler. O efeito físico de preenchimento das partículas de RCMG, que promove o melhor empacotamento das partículas, também resulta em uma diminuição da porosidade aparente.

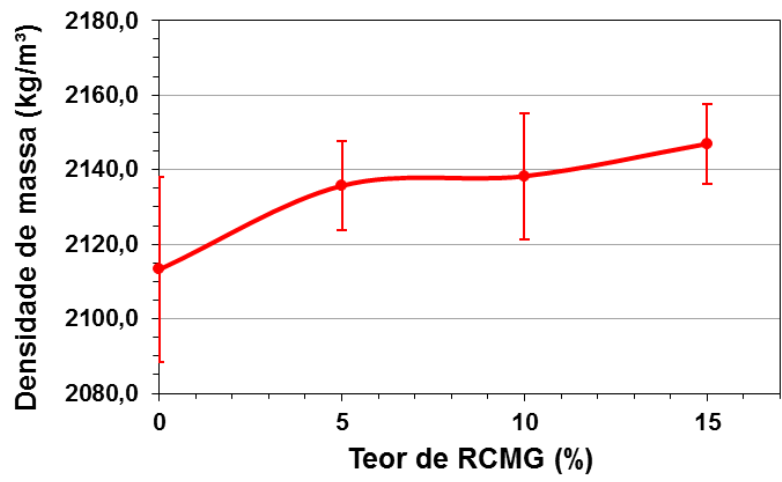

(a)

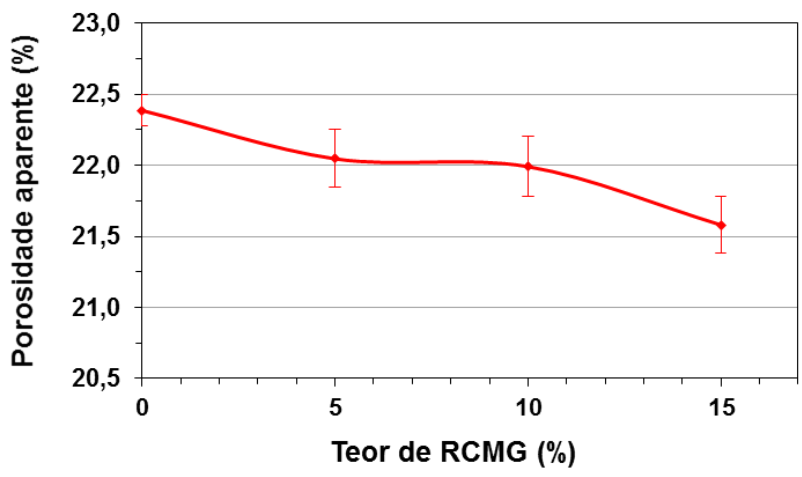

(b)

Figura 5 - (a) Densidade aparente e (b) porosidade aparente das argamassas aos 28 dias. 


\subsubsection{Absorção de água por capilaridade}

Os valores dos coeficientes de absorção capilar das argamassas estudadas, aos 28 dias, são apresentados na Figura 6. Nota-se que a absortividade não sofre alterações significativas até o teor de $5 \%$ de adição, quando esse parâmetro cresce em função do aumento da quantidade de resíduo adicionada. A maior quantidade de partículas finas tende a reduzir o diâmetro dos poros capilares, levando ao aumento da taxa de absorção de água. Esse comportamento também foi observado pro Silva (2006), que estudou argamassas mistas de cal e cimento e constatou que, naquelas em que foi acrescentado material pulverulento (areia britada de rocha calcária), a absortividade alcançou valores mais elevados. Isto acontece provavelmente devido à diminuição do raio dos capilares, levando a água a atingir maiores alturas nos corpos de prova, apesar da diminuição da porosidade aparente (Figura 5.b).

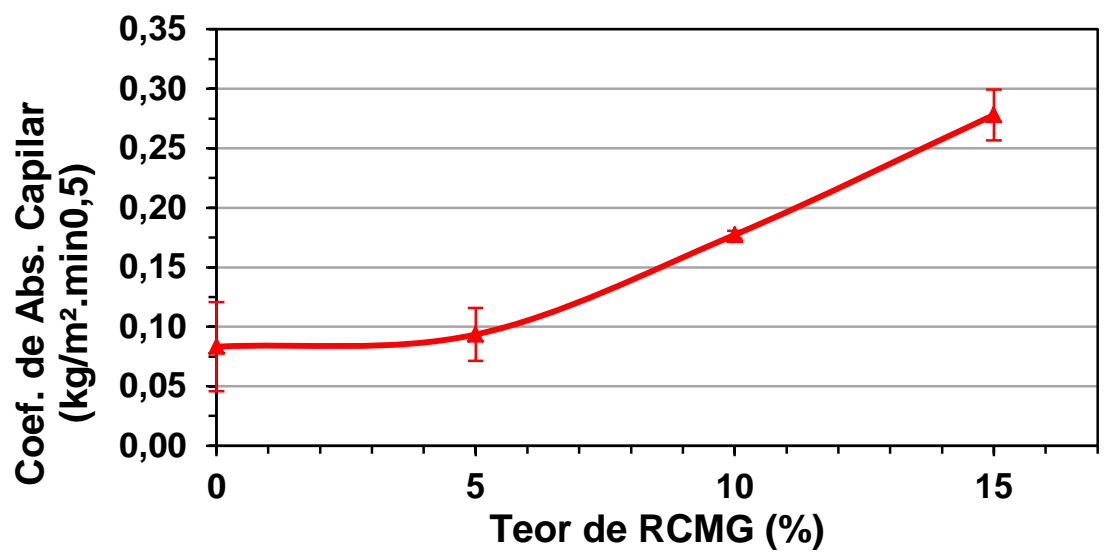

Figura 6 - Coeficientes de absorção capilar em função do teor de RCMG, aos 28 dias.

De acordo com Kendall et al. (1983) apud O'Farrell et al. (2001), os poros capilares podem chegar a alguns milímetros de comprimento, o que pode ser suficiente para iniciar fissuras e reduzir a resistência das argamassas. Visto que as composições contendo $10 \%$ e $15 \%$ de RCMG apresentaram elevados valores de absortividade, a 
queda da resistência verificada nestas argamassas pode ter sido também uma consequência da fragilidade imposta pelos "caminhos" de diâmetro capilar na matriz.

\subsubsection{Velocidade de propagação de onda ultrassônica e módulo de deformação dinâmico}

Os resultados obtidos no ensaio de determinação da velocidade de propagação de onda ultrassônica são apresentados na Figura 7.

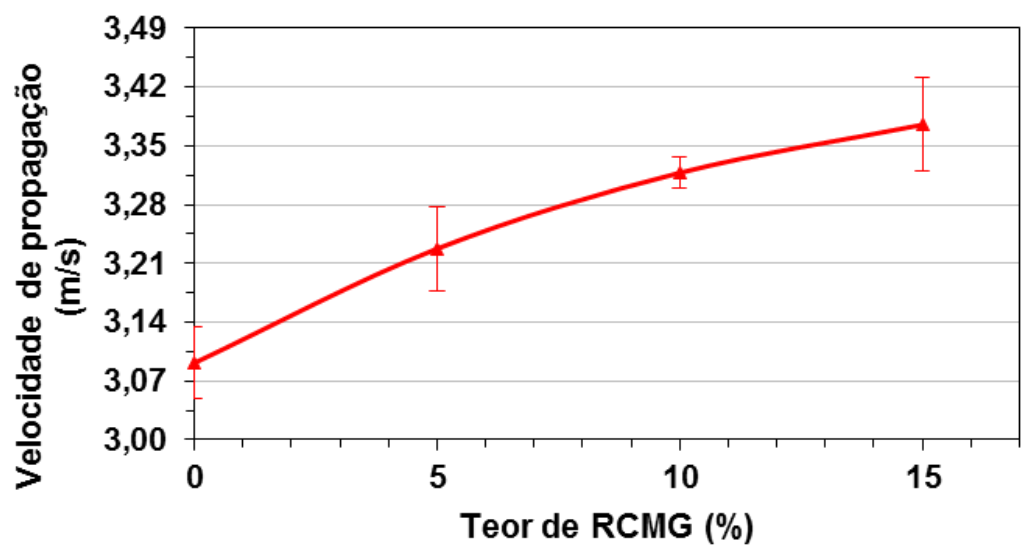

Figura 7 - Velocidade de propagação da onda ultrassônica nos corpos de prova de argamassa aos 28 dias.

Conforme previsto, os resultados obtidos para a velocidade de propagação do pulso ultrassônico são crescentes com o aumento teor de resíduo adicionado. Esse resultado é corroborado por Silva \& Campitelli (2006), os quais constataram que, com o aumento da compacidade do conjunto ligante/agregado, devido principalmente ao aumento do teor de finos na mistura, a velocidade de propagação da onda ultrassônica é maior. Isso também leva a um aumento no módulo de deformação, cujos valores são mostrados na Figura 8. 


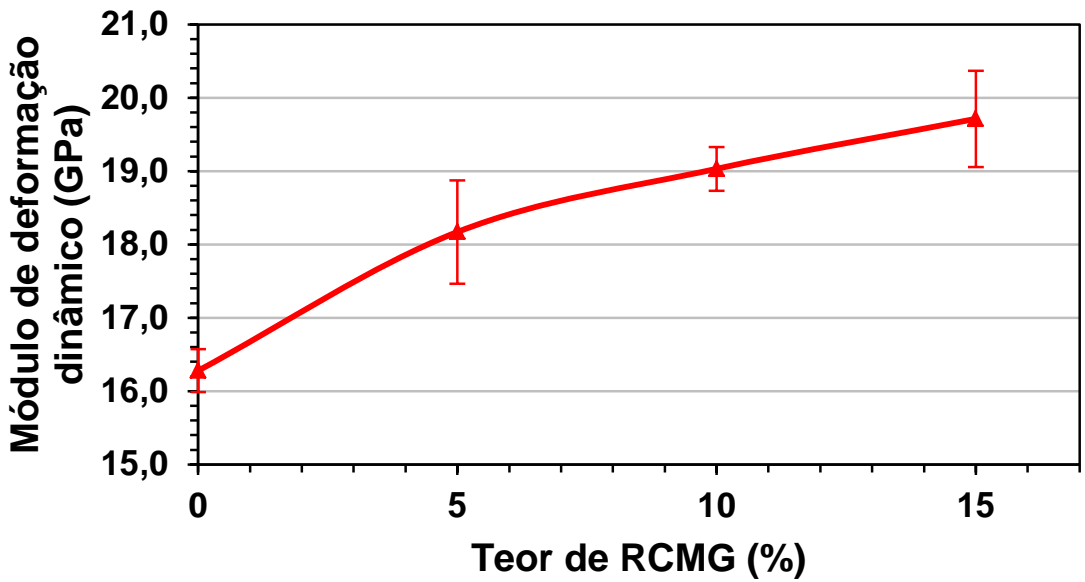

Figura 8 - Módulo de deformação dinâmico das argamassas, aos 28 dias, em função do teor de RCMG.

O módulo de deformação dinâmico é calculado em função da velocidade de propagação do pulso de ultrassom [Equação (7)], de modo que este parâmetro também aumenta com o incremento do teor de adição.

Visto que, como mostra a Equação 7, há uma relação direta entre módulo de deformação e massa específica, pode-se deduzir que, quanto maior a porosidade de um material, menor o seu módulo de deformação. Isso é comprovado pelos resultados experimentais, conforme mostra a Figura 9.

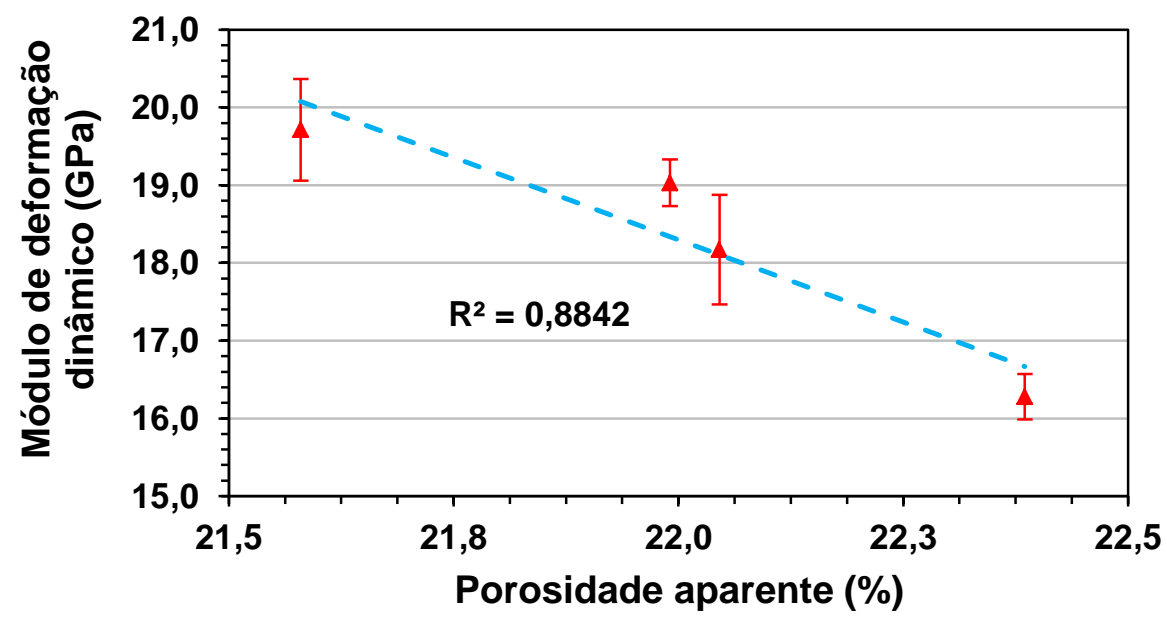

Figura 9 - Módulo de deformação dinâmico das argamassas, aos 28 dias, em função do teor de RCMG. 
Para a argamassa de referência, a porosidade aparente encontrada foi de $22,4 \%$, sendo 16,3 GPa o seu módulo de deformação. Na composição contendo 15\% de resíduo, no entanto, a redução da porosidade $(21,5 \%)$ acarretou uma elevação significativa na rigidez da argamassa (18,7 GPa), o que representa uma maior suscetibilidade à fissuração, devido à sua menor capacidade de se deformar.

\section{CONCLUSÕES}

- A partir da análise dos resultados obtidos, pode-se concluir que:

- A adição do RCMG promove um incremento na resistência mecânica das argamassas (resistência à flexão e à compressão), atingindo os valores mais elevados para o teor de $5 \%$ de adição;

- O aumento da resistência pode ser atribuído à melhora do empacotamento das partículas, expressa no aumento da densidade aparente, associada a uma redução da porosidade e consequente aumento da velocidade de propagação de onda ultrassônica para teores crescentes de RCMG;

- A introdução de teores crescentes do resíduo levou ao aumento da absortividade, visto que a presença de uma maior quantidade de partículas finas leva à redução do diâmetro dos poros capilares;

- A queda na resistência verificada para teores superiores a 5\% de adição pode ser decorrente da formação de aglomerações de partículas do resíduo durante a mistura (devido ao fato de ser um material muito fino, que retém parte da água que seria consumida nas reações de hidratação), assim como do aumento da formação de "caminhos" de diâmetro capilar na matriz, que podem ser suficientes para iniciar e propagar fissuras, prejudicando o desempenho mecânico;

- Com o aumento da densidade da argamassa para teores crescentes de adição, eleva-se também a sua rigidez, o que pode ser prejudicial para as aplicações em revestimentos; 
ISSN 1980-0827
Volume 9, Número 1, 2013

Aplicação de Novas Tecnologias Sustentáveis

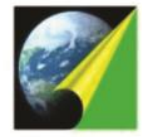

ANAP

- Os resultados atestam a viabilidade técnica do uso do RCMG como adição às argamassas. Com base nos parâmetros avaliados, $5 \%$ pode ser definido como 0 teor ótimo de adição.

\section{REFERÊNCIAS}

ABRELPE - ASSOCIAÇÃO BRASILEIRA DE LIMPEZA PÚBLICA E RESÍDUOS ESPECIAIS. Panorama dos Resíduos Sólidos no Brasil - 2011. São Paulo: ABRELPE, 2012.

ARUNTAŞ, H.; GÜRÜ, M.; DAYI, M.; TEKIN, I. Utilization of waste marble dust as an additive in cement production. Materials and Design, v.31, p. 4039-4042, 2010.

CASTRO, A. L.; PANDOLFELLI, V. C. Revisão: Conceitos de dispersão e empacotamento de partículas para a produção de concretos especiais aplicados na construção civil.

Cerâmica, v. 55, p. 18-32, 2009.

CORINALDESI, V.; MORICONI, G.; NAIK, T. R. Characterization of marble powder for its use in mortar and concrete. Construction and Building Materials, v.24, p. 113-117, 2010.

EUROPEAN COMMISSION. Priority funding areas. 2012. Disponível em: <http://ec.europa.eu/environment/eco-innovation/about/priorities/index_en.htm>. Acesso em jan. 2013.

GONÇALVES, J. P. Utilização do resíduo de corte de granito (RCG) como adição para produção de concretos. 2000, 135f. Dissertação (Mestrado em Engenharia Civil) Programa de Pós-Graduação em Engenharia Civil, Universidade Federal do Rio Grande do Sul, Porto Alegre.

JOHN, V. M. Reciclagem de resíduos na construção civil: Contribuição para metodologia de pesquisa e desenvolvimento. 2000, 113f. Tese (Livre Docência) Universidade de São Paulo, Escola Politécnica, Departamento de Engenharia de Construção Civil.

MENEZES, R. R.; FARIAS FILHO, J.; FERREIRA, H. S.; NEVES, G. A.; FERREIRA, H. C. Reciclagem de resíduos da construção civil para a produção de argamassas. Cerâmica, v.55, p. 263-270, 2009.

ONU - ORGANIZAÇÃO DAS NAÇÕES UNIDAS. Nosso Futuro Comum. 2. ed. Rio de Janeiro: Editora da Fundação Getúlio Vargas, 1991. 
O'FARRELL, M.; WILD, S.; SABIR, B. B. Pore size distribution and compressive strength of waste clay brick mortar. Cement and Concrete Composites, v. 23, p. 81-91, 2001.

SILVA, N. G. Argamassa de revestimento de cimento, cal e areia britada de rocha calcária. 2006, 180f. Dissertação (Mestrado em Construção Civil) - Programa de PósGraduação em Construção Civil, Universidade Federal do Paraná, Curitiba.

SILVA, N. G.; CAMPITELLI, V. C. Módulo de elasticidade dinâmico de argamassas de revestimento. In: II ENCONTRO DE ENGENHARIA E TECNOLOGIA DE CAMPOS GERAIS, Ponta Grossa, 2006. Anais eletrônicos. Disponível em: $<$ http://www.pg.cefetpr.br/ppgep/anais/artigos/eng civil/50\%20 MODULO\%20ELASTICIDADE\%20DINAM\%20ARGAMASS\%20REVESTIM.pdf > . Acesso em 17 dez. 2012.

SOUZA, U. E. L.; DEANA, D. F. Levantamento do estado da arte: Consumo de materiais. São Paulo, 2007. Disponível em $<$ http://www.habitacaosustentavel.pcc.usp.br/pdf/ D2-5 consumo materiais.pdf $>$. Acesso em: 07 ago. 2012. 